\title{
Hopfield Model of a Neuron Action under Dynamical Thresholds
}

\author{
A.K. Verma \\ Department of Mathematical \\ Sciences and Computer \\ Applications \\ Bundelkhand University, \\ Jhansi (U.P) India
}

\author{
Ruby Khan \\ Department of Mathematical \\ Sciences and Computer \\ Applications, \\ Bundelkhand University \\ Jhansi (U.P) India
}

\begin{abstract}
In this paper we present Hopfield model of a neuron dynamics given by the neuronic equation. In the first model second order neuronic equation describe the behavior of a neuron in the presence of some local positive feedback. The second model portray two neurons in which first order neuronic equation represents dynamics of the second neuron in the presence of a discharged pulse coded signal function from the first neuron. We have shown that the solution is bounded and the paths surrounding the equilibrium point are not closed curves in the phase plane. Some conditions ensuring the existence and uniqueness of the equilibrium point are derived.
\end{abstract}

\section{Keywords}

Dynamical thresholds, Equilibrium point, Convergence, Lyapunov functional, Homotopic mapping, Homotopy invariance principle, Bendixson's criteria, Limit cycles.

\section{INTRODUCTION}

Hopfield neural networks [1-2] have been extensively applied to study the diverse area like optimization, pattern recognition, model identification, Huffman codes, signal, image processing [3-9]. Hopfield neural network with distributed delay under dynamical thresholds was first introduced by Gopalsamy and Leung [10]. Later on Zhang, Li and Huo [11], Zhang and Li [12], Zhang and Huo [13], worked on more general, multineuron model with distributed delay under dynamical thresholds. All the models studied so far are based on first order neuronic equation with self feedback, however in the present work we have consider first and second order neuronic equation successively in the presence and absence of external stimulus. Neuronal dynamics in the presence of external stimulus is crucial to study since it describes a real picture of the neuron behavior. The neuronic equation considered by Caianiello and De Luca [14] is given by

$$
u(t+\tau)=H\left[A(t)-\int_{-\infty}^{t} k(t-s) u(s) d s-c\right],
$$

Above equation simplified by Gopalsamy and Leung [10], by the following assumptions

$$
\begin{aligned}
& \mathrm{u}(\mathrm{t}+\tau) \approx \mathrm{u}(\mathrm{t})+\tau \frac{\mathrm{du}(\mathrm{t})}{\mathrm{dt}} \\
& \mathrm{H}\left[\mathrm{A}(\mathrm{t})-\int_{-\infty}^{\mathrm{t}} \mathrm{k}(\mathrm{t}-\mathrm{s}) \mathrm{u}(\mathrm{s}) \mathrm{ds}-\mathrm{c}\right] \\
& =\mathrm{a} \tanh \left[\mathrm{u}(\mathrm{t})-\mathrm{b} \int_{-\infty}^{\mathrm{t}} \mathrm{k}(\mathrm{t}-\mathrm{s}) \mathrm{u}(\mathrm{s}) \mathrm{ds}-\mathrm{c}\right] .
\end{aligned}
$$

They study the delay differential equation of the form

$$
\dot{x}=\frac{d x}{d t}=-x(t)+a \tanh \left[x(t)-b \int_{0}^{\infty} k(s) x(t-s) d s-c\right],
$$

consider taylor's series expansion of $u(t+\tau)$ up to second order, from (1) (2) and (3) we derive a second order neuronic equation given by

$$
\ddot{x}+\frac{2}{\tau} \dot{x}+\frac{2}{\tau^{2}} x=\frac{2 a}{\tau^{2}} \tanh \left[x(t)-b \int_{0}^{\infty} k(s) x(t-s) d s-c\right],
$$

$\mathrm{k}$, a and $\mathrm{b}$ satisfy the condition

$$
\begin{aligned}
& \int_{0}^{\infty} \mathrm{k}(\mathrm{s}) \mathrm{ds}=1, \quad \int_{0}^{\infty} \mathrm{k}(\mathrm{s}) \mathrm{s} \mathrm{ds}<\infty \\
& \mathrm{a}>0, \quad \mathrm{~b}>0,
\end{aligned}
$$

for the meaning of various terms used above one can refer [10].The term $A(t)$ in (1) is the external stimulus to the neuron and has been taken as self feedback $x(t)$ in the argument of the tanh function in (4) and (5). 


\section{QUALITATIVE ANALYSIS OF THE SECOND ORDER NEURONIC EQUATION WITH SELF FEEDBACK}

Here we shall first discuss the behavior of a neuron action with self feedback given by (5).

Let $\quad \dot{x}=y$

In view of (8) equation (5) reduces to

$$
\begin{aligned}
& \dot{y}=-\frac{2}{\tau} y-\frac{2}{\tau^{2}} x \\
& +\frac{2 a}{\tau^{2}} \tanh \left[x(t)-b \int_{0}^{\infty} k(s) x(t-s) d s-c\right]
\end{aligned}
$$

\subsection{Boundedness of the solution}

In this part we shall discuss the boundedness of the solution of (8) and (9) using Lyapunov functional V (t) $=\mathrm{V}(\mathrm{x}, \mathrm{y})(\mathrm{t})$ defined by

$V(t)=|x(t)|+|y(t)|+\int_{0}^{t}|y(s) d s|+a b \int_{0}^{\infty} k(s)\left(\int_{t-s}^{t}|x(u) d u| d s\right.$,

calculating the upper right derivative $\mathrm{D}^{+} \mathrm{V}$ of $\mathrm{V}$ along the solution of (8) and (9)

$D^{+} V \leq|x(t)|+|y(t)|+|y(t)|+a b\left[|x(t)|-\int_{0}^{\infty} k(s)|x(t-s)| d s\right]$

$\mathrm{D}^{+} \mathrm{V} \leq|\mathrm{y}(\mathrm{t})|-\frac{2}{\tau}|\mathrm{y}(\mathrm{t})|-\frac{2}{\tau^{2}}|\mathrm{x}(\mathrm{t})|$

$+\frac{2 \mathrm{a}}{\tau^{2}}\left|\tanh \left[\mathrm{x}(\mathrm{t})-\mathrm{b} \int_{0}^{\infty} \mathrm{k}(\mathrm{s}) \mathrm{x}(\mathrm{t}-\mathrm{s}) \mathrm{ds}-\mathrm{c}\right]\right|$

$+a b\left[|x(t)|-\int_{0}^{\infty} k(s)|x(t-s)| d s\right]$

$\mathrm{D}^{+} \mathrm{V} \leq-\left[1-\frac{2}{\tau}\right]|\mathrm{y}(\mathrm{t})|+\left[1-\frac{2}{\tau^{2}}+\frac{2 \mathrm{a}}{\tau^{2}}+\mathrm{ab}\right]|\mathrm{x}(\mathrm{t})|$

$\mathrm{V}(\mathrm{x}, \mathrm{y})(\mathrm{t})+\left(1-\frac{2}{\tau}\right) \int_{0}^{\mathrm{t}}|\mathrm{y}(\mathrm{s})| \mathrm{ds}-\left(1-\frac{2}{\tau}+\frac{2 \mathrm{a}}{\tau^{2}}+\mathrm{ab}\right) \int_{0}^{\mathrm{t}}|\mathrm{x}(\mathrm{s})| \mathrm{ds}$

$\leq \mathrm{V}(\mathrm{x}, \mathrm{y})(0)$
It follows from $(10)$ and $(14)$ that $\mathrm{V}(\mathrm{t})$ is bounded on $(0, \infty)$ boundedness of $\mathrm{V}(\mathrm{t})$ on $(0, \infty)$ implies that $(\mathrm{x}, \mathrm{y})$ are bounded on $(0, \infty)$.

\subsection{Uniqueness of the equilibrium point}

Taking a cue from Cronin [15] work on the topological degree theory for the nonlinear mapping, some authors ( Zhang and Li [12], Cao and Wang [16]) use this theory to find the existence and uniqueness of the equilibrium point of the neuronic equation representing multineuron model. In the following lines our work is based on the paper by Zhang and Li[12], for the definition and terms used here one can refer them.

Theorem 2.2.1. The system of equations (8) and (9) has a unique equilibrium point subject to the following conditions (15) and (16).

$\tanh \mathrm{x}: \mathrm{R} \rightarrow \mathrm{R}$ is globally Lipschitz with Lipschitz constant $\mathrm{L}>0$, that is

$\left|\tanh \left(\mathrm{x}_{1}\right)-\tanh \left(\mathrm{x}_{2}\right)\right| \leq \mathrm{L}\left|\mathrm{x}_{1}-\mathrm{x}_{2}\right|, \quad \forall \mathrm{x}_{1}, \mathrm{x}_{2} \in \mathrm{R}$.

There exists $\varepsilon>0$ such that

$\varepsilon=1-\mathrm{a} L|1-\mathrm{b}|$

The equilibrium points of (8) and (9) are given by

$$
\begin{aligned}
& \left.\stackrel{*}{\mathrm{x}}=\mathrm{a} \tanh [(1-\mathrm{b}))^{*} \mathrm{x}-\mathrm{c}\right] \\
& \mathrm{y}=0
\end{aligned}
$$

Let

$f(x)=x-a \tanh [(1-b) x-c]$,

the solution of $f(x)=0$ are the equilibrium point of (8) and (9). We define a homotopic mapping

$H(x, \lambda)=\lambda f(x)+(1-\lambda) x$

$=x-a \lambda \tanh [(1-b) x-c]$

$|H(x, \lambda)|=|x-a \lambda \tanh [(1-b) x-c]|$

$\geq|x|-a \lambda|\tanh [(1-b) x-c]|$

$=|x|-a \lambda|\tanh [(1-b) x-c]-\tanh (-c)+\tanh (-c)|$ 
$\geq|x|-a \lambda|\tanh [(1-b) x-c]-\tanh (-c)|-a \lambda|\tanh (-c)|$,

by (15) we have

$H(x, \lambda) \geq|x|-a \lambda L|(1-b)||x|-a \lambda|\tanh (-c)|$

$=\lambda[1-\mathrm{a} \mathrm{L}|(1-\mathrm{b})|]|\mathrm{x}|-\mathrm{a} \lambda|\tanh (-\mathrm{c})|$

$=\lambda \varepsilon|\mathrm{x}|-\mathrm{a} \lambda|\tanh (-\mathrm{c})|$,

with the help of (16) above inequality is modified.

Let

$\eta=|\tanh (-\mathrm{c})|$

In view of above equation (24) reduces to

$|\mathrm{H}(\mathrm{x}, \lambda)| \geq \lambda \varepsilon|\mathrm{x}|-\mathrm{a} \lambda \eta$

Let

$\mathrm{U}=\left\{\mathrm{x}|\mathrm{x}|<\frac{(\mathrm{a} \eta+1)}{\varepsilon}\right\}$.

It follows from (27) that for any $\mathrm{x} \in \partial \mathrm{U}$, there exist $\mathrm{x}_{\mathrm{i}}$ such that

$\mathrm{x}_{\mathrm{i}}=\frac{(\mathrm{a \eta}+1)}{\varepsilon}$.

$|\mathrm{H}(\mathrm{x}, \lambda)| \geq \lambda \varepsilon\left|\mathrm{x}_{\mathrm{i}}\right|-\mathrm{a} \lambda \eta$

In view of (28) we obtain for any $\lambda \in(0,1]$

$|\mathrm{H}(\mathrm{x}, \lambda)| \geq \lambda>0$

which implies that $H(x, \lambda) \neq 0$ for any $x \in \partial U$ and $\lambda \in(0,1]$. If $\lambda=0$ from (20) we have $H(x, \lambda)=i_{d}(x)=x \neq 0$ for any $x \in \partial U$ here $\mathrm{i}_{\mathrm{d}}$ is identity mapping, hence $\mathrm{H}(\mathrm{x}, \lambda) \neq 0$ for any $\mathrm{x} \in \partial \mathrm{U}$ and $\lambda \in$ $(0,1]$. From the definition of topological degree one can show that $\operatorname{deg}\left(\mathrm{i}_{\mathrm{d}}, \mathrm{U}, 0\right)=1$, also from homotopy invariance theorem [15] we have deg $(f, U, 0)=\operatorname{deg}\left(i_{d}, U, 0\right)=1$. By the topological degree theory we conclude that the equation $\mathrm{f}(\mathrm{x})=0$ has at least a solution in $U$, therefore (8) and (9) has at least an equilibrium point .

In the next few lines we shall prove uniqueness of the equilibrium point $\left(x^{*}, 0\right)$ of $(8)$ and $(9)$. Suppose $\left(z^{*}, 0\right)$ is also an equilibrium point of (8) and (9) then we have $\mathrm{z}(\mathrm{t})=\mathrm{a} \tanh [(1-\mathrm{b}) \mathrm{z}(\mathrm{t})-\mathrm{c}]$

$\left.\stackrel{*}{*} \mathrm{x}^{-\mathrm{z}}=\mathrm{a}\left[\tanh \left[(1-\mathrm{b}) \mathrm{x}^{*}(\mathrm{t})-\mathrm{c}\right]-\tanh \left[(1-\mathrm{b}) \mathrm{z}^{*} \mathrm{t}\right)-\mathrm{c}\right]\right]$

with the help of (15)

$\left|\begin{array}{lr}* & * \\ \mathrm{x} & -\mathrm{z}\end{array}\right| \leq \mathrm{aL}\left|(1-\mathrm{b})\left(\begin{array}{rr}* & * \\ \mathrm{x} & -\mathrm{z}\end{array}\right)\right|$

$\left|\begin{array}{rr}* & * \\ \mathrm{x} & -\mathrm{z}\end{array}\right|[1-\mathrm{aL}|(1-\mathrm{b})|] \leq 0$.

In view (16), we obtain $\mathrm{x}=\mathrm{z}$, therefore system of equations (8) and (9) has a unique equilibrium point.

\subsection{Nature of the solution}

Here we shall analyze the nature of path near the equilibrium points of (8) and (9), by applying Bendixson's criteria [17] for planar dynamical systems. The equations (8) and (9) can be rewritten as

$\mathrm{g}(\mathrm{x}, \mathrm{y}) \equiv \dot{\mathrm{x}}=\mathrm{y}$

$$
\begin{aligned}
& \mathrm{h}(\mathrm{x}, \mathrm{y}) \equiv \dot{\mathrm{y}}=-\frac{2}{\tau} \mathrm{y}-\frac{2}{\tau^{2}} \mathrm{x} \\
& +\frac{2 \mathrm{a}}{\tau^{2}} \tanh \left[\mathrm{x}(\mathrm{t})-\mathrm{b} \int_{0}^{\infty} \mathrm{k}(\mathrm{s}) \mathrm{x}(\mathrm{t}-\mathrm{s}) \mathrm{ds}-\mathrm{c}\right]
\end{aligned}
$$

$\operatorname{div}[\mathrm{g}, \mathrm{h}]=\frac{\partial \mathrm{g}}{\partial \mathrm{x}}+\frac{\partial \mathrm{h}}{\partial \mathrm{y}}$

$\operatorname{div}[\mathrm{g}, \mathrm{h}]=-\frac{2}{\tau}<0$

Since $\tau>0$ therefore from Bendixson's criteria we conclude that the system of equations (8) and (9) has no closed orbits.

The differential equation of the paths of (8) and (9) is given by

$$
\frac{d x}{d y}=\frac{y}{-\frac{2}{\tau} y-\frac{2}{\tau^{2}} x+\frac{2 a}{\tau^{2}} \tanh \left[x(t)-b \int_{0}^{\infty} k(s) x(t-s) d s-c\right]},
$$

equation (39) is unchanged when $(x, y)$ is replaced by $(-x,-y)$ and $(-x, y)$ is replaced by $(x,-y)$. This means that the curve given 
by (39) is symmetrical in the phase plane (x,y) and the paths in the first and second quadrant are similar to paths in the third and fourth quadrant respectively. Path is horizontal when they cross the $\mathrm{x}$-axis and becomes vertical as they cross the curve.

$\tau \mathrm{y}+\mathrm{x}-\mathrm{a} \tanh \left[\mathrm{x}(\mathrm{t})-\mathrm{b} \int_{0}^{\infty} \mathrm{k}(\mathrm{s}) \mathrm{x}(\mathrm{t}-\mathrm{s}) \mathrm{ds}-\mathrm{c}\right]=0$.

By an inspection of the signs of the right sides of the (8) and (9) shows that all paths are directed to the right above the $\mathrm{x}$-axis and to the left below the $\mathrm{x}$-axis and move downwards or upwards according as

$\tau y+x>a \tanh \left[x(t)-b \int_{0}^{\infty} k(s) x(t-s) d s-c\right]$

or

$\tau y+x<a \tanh \left[x(t)-b \int_{0}^{\infty} k(s) x(t-s) d s-c\right]$

\section{QUALITATIVE ANALYSIS OF THE FIRST ORDER NEURONIC EQUATION WITHOUT SELF FEEDBACK}

In this model we examine qualitatively the first order neuronic equation in the presence of external stimulus without any self feedback. We are presenting two neuron model where output from the first neuron becomes external stimulus for the second neuron. The external stimulus is the pulse coded signal function which originate from a neuron and propagate down the axon on their passage to the synaptic junction. The neuronic systems use multiple electrochemical mechanism to intensify these pulses. The pulse coded signal function consider by Kosko [18,pp.5051] is given by the solution of the first order linear inhomogeneous differential equation.

$y(t)+p(t) y(t)=q(t)$

where $\mathrm{q}(\mathrm{t})$ is the bipolar pulse function given by

$q(t)=\left\{\begin{array}{rc}1 & \text { if a pulse arrives at } t \\ -1 & \text { if no pulse arrives at } t\end{array}\right.$

Let us assume that $\mathrm{p}(\mathrm{t})=1$ for all $\mathrm{t}$. Now (40) reduces to

$y(t)=-y(t)+1$
Integrating

$$
\mathrm{y}(\mathrm{t})=1+\mathrm{c}_{1} \mathrm{e}^{-\mathrm{t}}
$$

where $\mathrm{c}_{1}$ is the integration constant. When $\mathrm{t} \rightarrow 0 \Rightarrow \mathrm{y}(\mathrm{t}) \rightarrow 1+\mathrm{c}_{1}$, and whereas $\mathrm{t} \rightarrow \infty \Rightarrow \mathrm{y}(\mathrm{t}) \rightarrow 1$, therefore $\mathrm{y}(\mathrm{t})$ is bounded for any $\mathrm{t}$ $\in[0, \infty]$.

The neuronic equation (4) is the presence of external stimulus with no self feedback is given by

$\dot{x}(t)=-x(t)+a \tanh \left[y(t)-b \int_{0}^{\infty} k(s) x(t-s) d s-c\right]$

\subsection{Boundedness of the solution}

In this part we shall discuss the boundedness of the solution of (42) and (44) using Lyapunov function, consider a Lyapunov functional $V(t)=V(x, y)(t)$ defined by

$V(t)=|x(t)|+|y(t)|+a \int_{0}^{t}|y(s)| d s+a b \int_{0}^{\infty} k(s)\left(\int_{t-s}^{t}|x(u)| d u\right) d s$,

calculating the upper right derivative $\mathrm{D}^{+} \mathrm{V}$ of $\mathrm{V}$ along the solution of (42) and (44)

$\mathrm{D}^{+} \mathrm{V} \leq|\dot{\mathrm{x}}(\mathrm{t})|+|\dot{y}(\mathrm{t})|+\mathrm{a}|\mathrm{y}(\mathrm{t})|+\mathrm{ab}\left[|\mathrm{x}(\mathrm{t})|-\int_{0}^{\infty} \mathrm{k}(\mathrm{s})|\mathrm{x}(\mathrm{t}-\mathrm{s})| \mathrm{ds}\right]$

substituting the value of $\mathrm{x}(\mathrm{t})$ from (44) we obtain.

$$
\begin{aligned}
& D^{+} V \leq-|x(t)|+a \mid \tanh \left[y(t)-b \int_{0}^{\infty} k(s) x(t-s) d s-c\right] \\
& +|y(t)|+a|y(t)|+a b\left[|x(t)|-\int_{0}^{\infty} k(s)|x(t-s)| d s\right]
\end{aligned}
$$

$D^{+} V \leq-|x(t)|+a|y(t)|+|y(t)|+a|y(t)|+a b|x(t)|$

$$
D^{+} V \leq-(1-a b)|x(t)|+2 a|y(t)|+|y(t)|
$$

Hence 
$\mathrm{V}(\mathrm{x}, \mathrm{y})(\mathrm{t})+(1-\mathrm{ab}) \int_{0}^{\mathrm{t}}|\mathrm{x}(\mathrm{s})| \mathrm{ds}-2 \mathrm{a} \int_{0}^{\mathrm{t}}|\mathrm{y}(\mathrm{s})| \mathrm{ds}-|\mathrm{y}(\mathrm{t})|$

$\leq \mathrm{V}(\mathrm{x}, \mathrm{y})(0)$

It follows from (45) and (50) that $\mathrm{V}(\mathrm{t})$ is bounded on $(0, \infty)$ this implies that $(\mathrm{x}, \mathrm{y})$ are bounded on $(0, \infty)$.

\subsection{Uniqueness of the equilibrium point}

The equilibrium points of the system of equations (42) and (44) are given by

$$
*
$$$$
\mathrm{y}=1
$$

$\stackrel{*}{\mathrm{x}}=\mathrm{a} \tanh [\mathrm{y}-\mathrm{bx}-\mathrm{c}]$

substituting $\quad{ }^{*}=1$ in (51) we obtain

$\stackrel{*}{\mathrm{x}}=\mathrm{a} \tanh [1-\mathrm{bx}-\mathrm{c}]$.

With the help of topological degree theory used in section 2.2 we can prove that their exists a unique equilibrium point of (42) and $(44)$ given by $\left({ }^{*}, 1\right)$.

\subsection{Nature of the solution}

Here we shall study the nature of path near the equilibrium point of (42) and (44). We rewrite (42) and (44) as

$\mathrm{h}(\mathrm{x}, \mathrm{y}) \equiv \dot{\mathrm{y}}(\mathrm{t})=-\mathrm{y}(\mathrm{t})+1$

$g(x, y) \equiv \dot{x}(t)=-x(t)+a \tanh \left[y(t)-b \int_{0}^{\infty} k(s) x(t-s) d s-c\right]$

$\operatorname{div}[\mathrm{g}, \mathrm{h}]=\frac{\partial \mathrm{g}}{\partial \mathrm{x}}+\frac{\partial \mathrm{h}}{\partial \mathrm{y}}$

In view of (42) and (44) we obtain

$$
\begin{aligned}
& \operatorname{div}[g, h]=-1-a b \operatorname{sech}\left[y(t)-b \int_{0}^{\infty} k(s) x(t-s) d s\right]-1 \\
& =-2-a b\left(1-\tanh ^{2}\left[y(t)-b \int_{0}^{\infty} k(s) x(t-s) d s\right]\right)
\end{aligned}
$$

$=-2-a b\left[1-\left(\frac{g+x}{a}\right)^{2}\right]$,

from (55) we derive an inequality

$-1 \leq\left(\frac{g+x}{a}\right) \leq 1$,

above inequality also satisfy

$0 \leq\left(\frac{g+x}{a}\right)^{2} \leq 1$

Now the following case arises since $\mathrm{a}>0, \mathrm{~b}>0$

case(i)

$\left(\frac{\mathrm{g}+\mathrm{x}}{\mathrm{a}}\right)^{2}=1$

case(ii)

$\left(\frac{g+x}{a}\right)^{2}=0$,

case(iii)

$0<\left(\frac{\mathrm{g}+\mathrm{x}}{\mathrm{a}}\right)^{2}<1$

In all the cases (i)-(iii), (59) yields $\operatorname{div}[\mathrm{g}, \mathrm{h}]<0$, therefore from Bendixson's criteria we conclude that the system of equations (42) and (44) has no closed orbits. From (42) and (44) we derive a differential equation

$\frac{d x}{d y}=\frac{-x(t)+a \tanh \left[y(t)-b \int_{0}^{\infty} k(s) x(t-s) d s-c\right]}{-y(t)+1}$

In the phase plane (x,y) curve given by (65) is not symmetrical. The path is horizontal as they cross the curve

$x(t)=a \tanh \left[y(t)-b \int_{0}^{\infty} k(s) x(t-s) d s-c\right]$ and is vertical when they cross the line $y=1$. By inspection of the signs of the right side of (42) and (44) shows that path move downwards or upwards according as $\mathrm{y}>1$ or $\mathrm{y}<1$ and paths are directed to the right or left provided 


$$
x(t)<\operatorname{atanh}\left[y(t)-b \int_{0}^{\infty} k(s) x(t-s) d s-c\right]
$$

or

$$
x(t)>a \tanh \left[y(t)-b \int_{0}^{\infty} k(s) x(t-s) d s-c\right]
$$

\section{CONCLUSION}

In the foregoing sections we have investigated the two models of a neuron action under dynamical thresholds. In the first model behavior of a single neuron is studied in the absence of external stimulus with positive self feedback, section two gives the detailed analysis of this model. In the second model we consider neuron dynamics in the presence of external stimulus that is pulse coded signal function, section three describes this model. In both these models it is observed that the solution of neuronic equation is bounded and has no limit cycles, this implies that it has no oscillatory solutions. These models are relevant in many realistically significant problems such as the study of the dynamics of biological neurons and in the design of the stable artificial neural networks. Our ideas can be extended to a class of cellular neural networks consisting of multineuron model

\section{REFERENCES}

[1] Hopfield, J.J. 1982. Neural networks and physical systems with emergent collective computational abilities, Proc. Nat. Acad. Sci. USA, Vol.79, no. 8,pp. 2554-2558.

[2] Hopfield, J.J.1984. Neurons with graded response have collective computational properties like those of two-state neurons, Proc. Nat. Acad. Sci. USA, Vol.81,no.10, pp. 3088-3092.

[3] Hopfield, J.J. and Tank, D.W.1985. Neural computation of decisions in optimization problems, Biological Cybernetics, Vol .52, no.3, pp. 141-152.

[4] Fabris, F. and Della, G. Riccia.1993. An application of the Hopfield model to Huffman codes, IEEE Trans. Information Theory, Vol.39, no.3,pp. 1071-1076.

[5] Cao, J.2001. Global stability conditions for delayed CNNs, IEEE Trans. Circuits Syst.I,Vol. 48, pp. 1330-1333.
[6] Driessche, P. V. D and Zou, X.1998. Global attractivity in delayed Hopfield neural network models, SIAM J. App. Math, Vol .58, no. 6,pp. 1878-1890.

[7] Farrell, J. A and Michel, A. N.1990. A synthesis procedure for Hopfield's continuous-time associative memory, IEEE Trans. Circuits Syst, Vol.37, pp. 877-884.

[8] Guan, Z. H. and Chen, G. R.1999. On delayed impulsive Hopfield neural networks, Neural Networks, Vol.12, no. 2, pp. 273-280.

[9] Mohamad, S.2003. Convergence dynamics of delayed Hopfield type neural networks under almost periodic stimuli, Acta Appl. Math,Vol. 76. no. 2, pp. 117-135.

[10] Gopalsamy, K. and Leung, I. K. C.1997. Convergence under dynamical thresholds with delays, IEEE Trans. Neural Network,Vol. 8, no.2, pp. 341-348.

[11] Zhang, F. Y. Li, W. T. and Huo, H. F.2003. Global stability of a class of delayed cellular neural networks with dynamical thresholds, International Journal of Applied Mathematics,Vol. 13, no. 4,pp. 359-368.

[12] Zhang, F. Y. and Li, W. T.2005. Global stability of delayed Hopfield neural networks under dynamical threshold, Discrete Dynamics in Nature and Society, Vol.2005, no.1, pp. 1-17.

[13] Zhang, F. Y. and Huo, H. F.2006. Global stability of Hopfiled neural networks under dynamical thresholds with distributed delays, Discrete Dynamics in Nature and Society, Vol.2006, Article ID 27941, pp. 1-11.

[14] Caianiello, E. R. and De Luca, A.1966. Decision equation for binary systems: Application to neuronal behavior, Kybernetik,Vol. 3, pp.33-40.

[15] Cronin, J.1964. Fixed points and topological degree theory in nonlinear analysis, Providence, RI, Amer.Math.Soc.

[16] Cao, J and Wang, J.2003. Global asymptotic stability of a general class of recurrent neural networks with timevarying delays, IEEE.Trans. Circuits Syst.I,Vol.no1,pp.3444.

[17] Perko, L.1991. Differential Equations and Dynamical Systems, Springer- Verlag, New York.

[18] Kosko, B.2005. Neural Networks and Fuzzy Systems: A Dynamical Systems Approach to Machine Intelligence, Prentice-Hall of India Private Limited. 